\title{
Factors affecting betacyanin stability in juice of LD5 Red-fleshed dragon fruit (Hylocereus polyrhizus)
}

\author{
Anh H. T. Nguyen, Mai T. P. Phung, Trang T. T. Nguyen, \\ Thuy T. P. Nguyen, Huan T. Phan, \& Ngan N. T. Trinh* \\ Faculty of Food Science and Technology, Nong Lam University, Ho Chi Minh City, Vietnam
}

ARTICLE INFO
Research Paper
Received: September 20, 2018
Revised: November 11, 2018
Accepted: December 02, 2018
Keywords
Betacyanin
Binh Thuan dragon fruit
Colourant stability
LD5 variety
Fruit juice
*Corresponding author
Trinh Ngoc Thao Ngan
Email: tntngan@hcmuaf.edu.vn

\begin{abstract}
In Binh Thuan province (Vietnam), the red-fleshed dragon fruit (Hylocereus polyrhizus), concretely LD5 variety majorly grows and contains a large amount of betacyanin, a natural colourant that potentially applied to many products in the food industry. In this study, the processing factors possibly influencing the betacyanin stability in the red-fleshed dragon fruit juice were in turn investigated. The heating treatment included 2 factors: temperature $(65,75$ and $85^{\circ} \mathrm{C}$ ) and heating time (10, 20 and 30 minutes); while the $\mathrm{pH}$ values ranged between 3.0 to 7.0 and the ascorbic acid addition varied in concentrations $(0.1,0.2,0.3,0.4$ and $0.5 \% \mathrm{w} / \mathrm{w})$. The processed fruit juice was stored in different packaging materials (plastic and glass) with and without light exposure for 5 weeks to monitor the retained betacyanin. The results showed that the betacyanin was remained with the highest proportion $(0.84 \pm 0.02)$ at $0.3 \%$ ascorbic acid addition, $\mathrm{pH}$ 4.0 and heat treatment at $65^{\circ} \mathrm{C}$ for 10 minutes. In storage without light exposure, both plastic and glass packaging materials kept efficiently betacyanin in fruit juice. However, the glass material represented better efficiency in the betacyanin remaining than the plastic material did.
\end{abstract}

Cited as: Nguyen, A. H. T, Phung, M. T. P., Nguyen, T. T. T., Nguyen, T. T. P, Phan, H. T., \& Trinh, N. N. T. (2018). Factors affecting betacyanin stability in juice of LD5 Red-fleshed dragon fruit (Hylocereus polyrhizus). The Journal of Agriculture and Development 17(6), 72-76.

\section{Introduction}

Dragon fruit belongs to the Cactaceae family that widely grown in several countries such as Taiwan, Vietnam and Malaysia (Nur' Aliaa et al., 2010). In Vietnam, it is one of the popular fruitbearing trees with 2 available types: Hylocereus undatus (H. undatus) with pink skin and whiteflesh; and Hylocereus polyrhizus (H. polyrhizus) with pink skin and red flesh. In recently, the redfleshed dragon fruit has been extensively planted in many provinces such as Long An, Ninh Thuan, Tien Giang etc due to several benefits in terms of health, sensorial values, economic issues, etc. With more than 26,000 ha of growing dragon fruit, Binh Thuan Province has the largest area allocated to the fruit in the country, according to province's Agriculture and Rural Development Department. The dragon fruit planting area will predictably have increased to 28,000 ha with 750 000 tons of production by 2020 (Tran \& Nguyen, 2017). The LD5 dragon fruit, a natural source of antioxidants and attractive colour betacyanin, mostly grows in Binh Thuan due to a high yield, good adaptation to the natural environment and (strong) resistance against diseases.

Betacyanin, made of water-soluble nitrogencontaining pigments (betalains), is a set compound contributing fundamentally to the colour of dragon fruit $H$. polyrhizus (Rebecca et al., 2010). It is unstable and easily degrades or breaks down into the degradation product such as cyclodopa 5 -O- $\beta$-glucoside (colourless) and betalamic acid (bright yellow), leading to the discoloration 
of the pigments (Herbach et al., 2004). Several factors including heat, oxygen, light, $\mathrm{pH}$ and moisture are reported to have significant effects on the betacyanin stability (Woo et al., 2011). In addition, the discoloration rate of red colour from garambullo tree (Myrtillocactus geometrizans), from red-fleshed dragon fruits (H. polyrhizus) was also diminished by the addition of some antioxidants such as ascorbic acid, citric acid (Reynoso et al., 1997; Wong \& Siow, 2015).

The aim of this study was to investigate the effects of heat treatment, $\mathrm{pH}$ and ascorbic acid concentration on the betacyanin stability. The effects of storage conditions including light exposure and packaging material were also studied within 5 weeks at ambient temperature. These results are the preliminary findings for the further application into fruit juice process, that potentially contributes to value addition for red-fleshed dragon fruits in Binh Thuan Province.

\section{Materials and Methods}

\subsection{Sample preparation}

Red-fleshed dragon fruits were collected from farmer households in Binh Thuan province with the similarity in terms of maturity, weight and without any defects and/or crushes. The fresh fruits were stored at cool temperature (15$20^{0} \mathrm{C}$ ) before use. Red-fleshed dragon fruits were washed, peeled before collecting pulp. The pulp then crushed directly to collect the dragon fruit. The juice was centrifuged at $3000 \mathrm{~g}$ for 10 minutes (Z206A - Hermle - German) and filtered through a filter paper (Whatman) to remove the solid parts. The filtrate was then obtained to carry out the betacyanin analysis.

\subsection{Experiments}

Completely randomized design was serially applied to investigate the effects of heating condition, $\mathrm{pH}$, ascorbic acid concentration and storage condition. The research was carried out at Food Engineering Laboratory, Faculty of Food Science and Technology, Nong Lam University Ho Chi Minh City.

Effects of heating conditions: The filtered dragon fruit juices $(12 \mathrm{~mL})$ at natural $\mathrm{pH}$ in test tube were treated at various heating conditions including 65,75 and $85^{\circ} \mathrm{C}$ for 10,20 and 30 minutes in water bath. The time was counted since the center temperature rose up to the required temperature using the thermometer. The heated juices then cooled down in ice water and subsequently were subjected to betacyanin analysis.

Effects of $\mathrm{pH}$ : The filtered juice samples (12 $\mathrm{mL}$ ) were adjusted to $\mathrm{pH} 3.0 ; 4.0 ; 5.0 ; 6.0$ and 7.0 using $1 \mathrm{M} \mathrm{HCl}$ and $1 \mathrm{M} \mathrm{NaOH}$. All these samples were subjected to heat treatment at $650 \mathrm{C}$ for 10 minutes and cooled immediately in iced water. The betacyanin analysis was then carried out Effects of ascorbic acid addition: Different concentrations of ascorbic acid including 0 (control); 0.1 ; $0.2 ; 0.3 ; 0.4$ and $0.5 \%(\mathrm{w} / \mathrm{w})$ were added into the juices. All the juice samples were then adjusted to $\mathrm{pH} 4.0$ by $1 \mathrm{M} \mathrm{HCl}$ and $1 \mathrm{M} \mathrm{NaOH}$; subjected to heat treatment at $65^{\circ} \mathrm{C}$ for 10 minutes and cooled down in iced water before betacyanin analysis.

Effects of storage conditions: The dragon fruit juices treated with the optimal conditions from previous experiments were kept in 2 types of test tubes: the glass test tubes and the plastic test tubes. The glass ones were considered as imitation of glass packaging material, while the other represented for plastic packaging material. The tubes covered with aluminum-foil were the samples stored in light prevention condition; while the tubes without aluminum-foil were the samples stored in light exposure condition. All the samples were stored for 5 weeks at ambient temperature $\left(30 \pm 2{ }^{0} \mathrm{C}\right)$. The betacyanin analysis was determined after treating with heat and every week to compare the proportion of betacyanin retained during storage.

\subsection{Betacyanin analysis and retained beta- cyanin proportion}

The Mcllvaine buffer ( $\mathrm{pH}$ 6.5) prepared from $0.1 \mathrm{M}$ citric acid $(30 \mathrm{~mL})$ and $0.2 \mathrm{M}$ dibasic sodium phosphate $(70 \mathrm{~mL})$ was used to dilute the dragon fruit juice. The juice sample, diluted into 40 times by adding $0.1 \mathrm{~mL}$ of juice sample to $3.9 \mathrm{~mL}$ of Mcllvaine buffer solution, was analyzed with UVvis spectrophotometer (Shimadzu 1240, Japan). The wavelength was $540 \mathrm{~nm}$ which was tested preliminarily from $537 \mathrm{~nm}$ to $600 \mathrm{~nm}$ to attain the maximum absorbance. The Mcllvaine buffer solution with $4.0 \mathrm{~mL}$ (without sample) was a blank.

The concentration of betacyanin $(\mathrm{Bc})$ is expressed as the following equation:

$$
\mathrm{Bc}\left(\frac{\mathrm{mg}}{\mathrm{L}}\right)=\frac{\mathrm{A} \times \mathrm{F} \times \mathrm{MW} \times 1000}{\varepsilon \times \mathrm{l}}
$$




\section{Where:}

A: Absorption value at $\lambda=540 \mathrm{~nm}$

F: Dilution factor

MW: Molecular weight of betacyanin (550 $\mathrm{g} / \mathrm{mol})$

$\varepsilon$ : Molar extinction coefficient of betacyanin $(60,000 \mathrm{~L} /$ mole $\times \mathrm{cm})$

l: path length of the cuvette $(1 \mathrm{~cm})$

The retained betacyanin proportion was calculated by the ratio between the betacyanin content in the untreated juice and the betacyanin content in the juice treated by factors of experiment, as following:

Retained betacyanin proportion $=\frac{\mathrm{Bc}_{1}}{\mathrm{Bc}_{0}}$ Where:

$\mathrm{Bc}_{0}$ : the initial betacyanin content (e.i betacyanin in the untreated/natural juice)

$\mathrm{Bc}_{1}$ : the betacyanin content in the juices treated by the factors of experiments)

\subsection{Statistical analysis}

All experiments were carried out in triplicate. Calculation, tabulating and graphing of data were carried out using Microsoft Excel 2007 (Microsolft, USA). Statistical analysis was performed by using JMP software version 10.0 (SAS Institute Inc, USA). The difference was considered significant at $P<0.05$.

\section{Results and Discussion}

\subsection{Effects of heating treatment}

The betacyanin content remained in the juice after treating with heat is shown in Figure 1. Generally, heat treatment obviously caused decrease of betacyanin and the temperature has a significant effect on the retained betacyanin in the juice. The higher temperature applied, the less retained content in the juice was recorded. The betacyanin content decreased from initial content of $204.11 \pm$ $2.40(\mathrm{mg} / \mathrm{L})$ to $175.54 \pm 5.39 ; 140.85 \pm 10.79$ and $114.31 \pm 4.09(\mathrm{mg} / \mathrm{L})$ as heating at $65^{\circ} \mathrm{C}, 75^{0} \mathrm{C}$ and $85^{\circ} \mathrm{C}$ for 10 minutes, respectively $(P<0.05)$. The similar trend was also found when the fruit juices were subjected to heat for 20 and 30 minutes. Otherwise, the time fairly affected on the remained betacyanin content, particularly at the small variation in time. For examples, the juice heated at $65^{\circ} \mathrm{C}$ contained $175.54 \pm 5.39 ; 158.64$ \pm 13.03 and $145.62 \pm 10.48(\mathrm{mg} / \mathrm{L})$ correspond- ing to 10, 20 and 30 minutes, respectively. Interestingly, when the temperature increased up to $85^{0} \mathrm{C}$, the retained betacyanin content decreased dramatically as compared to the results at the other temperatures and did not depend on the heating time. According to Herbach et al. (2004), the heating could accelerate the degradation of betanlains (the main structure of betacyanin) to cyclo-dopa 5 -O- $\beta$-glucoside (colourless) and betalamic acid (bright yellow) by the bond cleavage, leading to the discoloration of the pigments. The results were supported by research of Reshmi et al. (2012): the betacyanin in basella alba fruit was maintained at 0,10 and $20^{\circ} \mathrm{C}$ and decreased when the temperature heated up from 40,50 and $60^{\circ} \mathrm{C}$ Similarly, Wong \& Siow (2015) reported the proportion of betacyanin retained decreased when the temperatures increased 65,75 and $85^{\circ} \mathrm{C}$ in the long heating time.

As a result, the heating condition at $65^{\circ} \mathrm{C}$ for 10 minutes was the optimal condition to remain efficiently the betacyanin content in the juice.

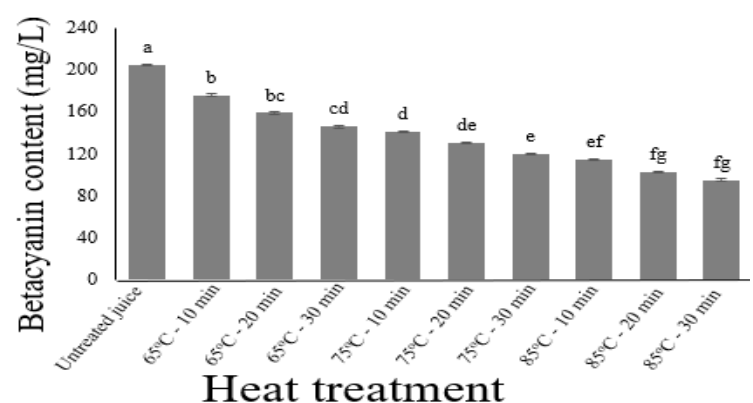

Figure 1. The betacyanin content in the different juice samples before and after heating.

\subsection{Effects of $\mathrm{pH}$}

Figure 2 obviously represents the significant effects of $\mathrm{pH}$ on the betacyanin stability based on the results of betacyanin content in the juice samples and the retained betacyanin proportion. The betacyanin content of $204.03 \pm 4.35(\mathrm{mg} / \mathrm{L})$ in the unheated juice decreased after heating to different amounts depending on the adjusted $\mathrm{pH}$ values. According to Reshmi et al. (2012), betacyanin was stable with red colour in neutral and slightly acidic media; on the contrary betacyanin was unstable and change colour from red into yellow in the alkaline medium at $\mathrm{pH}$ values upper 7.5. The acidic medium favored the connection between betalamic acid and cyclodopa-5-O- 
$\beta$-glucoside to form betacyanin (Azeredo, 2009). The proportion of betacyanin retained was found to be the highest at $\mathrm{pH} 4.0$ (with $0.87 \pm 0.01$ retained proportion of betacyanin) that was in consistent with the study of Herbach et al. (2007). But other researchers reported $\mathrm{pH} 5.0$ was the optimal value to support the betacyanin stability (Tang \& Norziah, 2010; Wong \& Siow, 2015). The betacyanin content of $\mathrm{pH} 3.0$ sample was the least at $118.98 \pm 1.21(\mathrm{mg} / \mathrm{L})$ with $0.58 \pm$ 0.01 retained proportion. It was explained by Azeredo (2009) that the $\mathrm{CO}_{2}$ removal forms 17decarboxybetanin with orange-red colour, or the dehydrogenation produces the neobetanin with yellow colour, leading to the pigment degradation. The $\mathrm{pH} 4.0$ was the optimal for the betacyanin stability in the LD5 red-fleshed dragon juice.

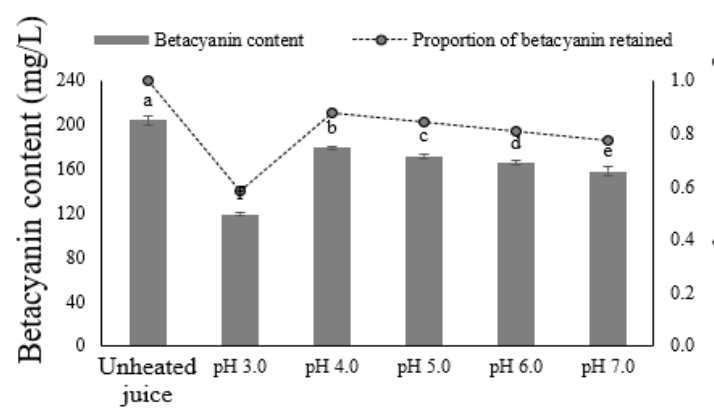

Figure 2. The betacyanin content and proportion of betacyanin retained in the juice samples after adjusting at different $\mathrm{pH}$ and heating.

\subsection{Effects of ascorbic acid addition}

Ascorbic acid has been well-known as an antioxidant due to its ability to combine with oxygen from surrounded environment - the main factor caused degradation of several sensitive compounds such as betacyanin (Attoe \& von Elbe, 1982). Figure 3 shows the slightly positive effects of ascorbic acid on the betacyanin content remaining in the LD5 red-fleshed dragon fruit juice after processing. Generally, the betacyanin content in the unheated juice $(203.79 \pm 3.01 \mathrm{mg} / \mathrm{L})$ reduced after heating process and in almost treatments the betacyanin proportion could be remained up to $75 \%$. Without ascorbic acid and adding 0.1 and $0.2 \%$ ascorbic acid, the proportions of betacyanin remained were $0.80 \pm 0.01$; $0.79 \pm 0.02$ and $0.82 \pm 0.01$, respectively without any significant difference $(P>0.05)$. The highest retained betacyanin proportion was 0.84 \pm 0.01 attained at $0.3 \%$ ascorbic acid addition with $171.18 \pm 3.35(\mathrm{mg} / \mathrm{L})$ betacyanin content. Interestingly, the increment in concentration up to $0.4 \%$ ascorbic acid did not further increase the proportion of betacyanin retained $(0.82 \pm 0.01)$, while $0.5 \%$ ascorbic acid addition did not show any positive effect on the retained betacyanin proportion $(0.78 \pm 0.02)$. This result supported to the research of Wong \& Siow (2015) that ascorbic acid efficiently remained the betacyanin at the concentrations less than $0.5 \%(\mathrm{w} / \mathrm{w})$.

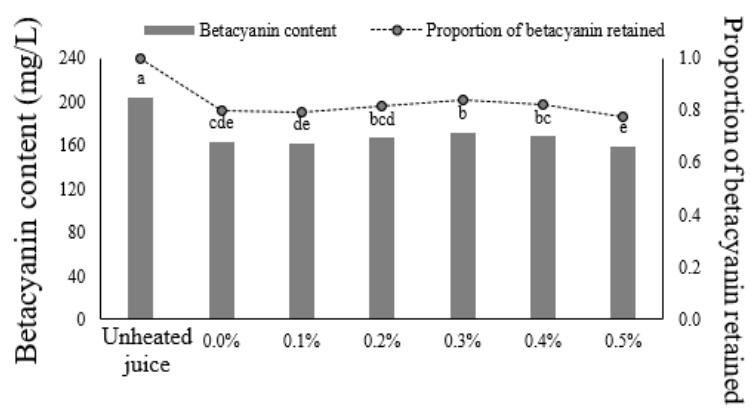

Figure 3. The betacyanin content and proportion of betacyanin retained in the juice samples after adding different ascorbic acid concentrations and heating.

\subsection{Effects of storage conditions}

Generally, the proportions of betacyanin retained decreased during the storage time for all the treatments with different rate (Figure 4). Obviously, during storage time, the juices in both plastic and glass test tubes in case of light exposure had the low retained betacyanin proportions and without any significant difference in results between these treatments in every week. The betacyanin content kept in the plastic tubes reduced down to almost half in the $1^{\text {st }}$ week storage $(0.57 \pm 0.02)$ and continuously to $0.51 \pm 0.03$, $0.46 \pm 0.03,0.39 \pm 0.03$ and $0.33 \pm 0.03$ at the $2^{\text {nd }}, 3^{\text {rd }}, 4^{\text {th }}$ and $5^{\text {th }}$ week, respectively. Similar trend was found in the juice sample stored in the glass test tube in light exposure. Otherwise, the juice in case of without light exposure showed the better remained betacyanin proportion, especially as juice was kept in the glass packaging material. The juice in plastic tubes remained $0.63 \pm 0.02$ betacyanin proportion in the $1^{\text {st }}$ week that slightly higher as compared to the formers; however, the proportion then in storage time was in the insignificant difference. The highest beta- 
cyanin proportions during storage were observed at the juice in glass test tubes with $0.90 \pm 0.01$ in the $1^{\text {st }}$ week, $0.76 \pm 0.03$ in the $2^{\text {nd }}$ week, $0.74 \pm$ 0.04 in the $3^{\text {rd }}$ week, $0.64 \pm 0.02$ in the $4^{\text {th }}$ week and $0.56 \pm 0.02$ in the last week. These findings were in agreement with the research conducted by Wong \& Siow (2015) who also studied about betacyanin stability in red-fleshed dragon fruit juice. According to Jackman \& Smith (1996), the pigment molecules absorb ultraviolet and visible light that excite $\pi$ electrons into the higher state $\left(\pi^{*}\right)$, resulted in the decrease of molecular stability.

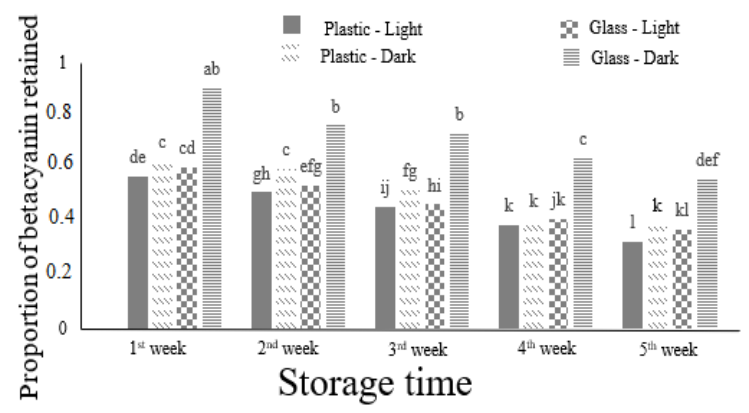

Figure 4. The retained proportion of betacyanin in the juice stored in different storage conditions during storage time.

\section{Conclusions}

The highest proportion of retained betacyanin was obtained from the dragon fruit juice that subjected to heat treatment at $65^{0} \mathrm{C}$ for $10 \mathrm{~min}$ utes, $\mathrm{pH} 4.0$ and $0.3 \%$ ascorbic acid addition. In storage, light exposure was an important factor that caused decrease of retained betacyanin in the fruit juice. In addition, the glass material represented better efficiency in the betacyanin remaining than the plastic material did.

\section{Acknowledgement}

This study was financially sponsored by Nong Lam University Ho Chi Minh City, Vietnam

\section{References}

Attoe, E. L., \& Von Elbe, J. H. (1982). Degradation kinetics of betanin in solutions as influenced by oxygen. Journal of Agricultural and Food Chemistry 30(4), 708-712.
Azeredo, H. (2009). Betalains: properties, sources, applications, and stability - a review. International Journal of Food Science \& Technology 44(12), 2365-2376.

Herbach, K. M., Maier, C., Stintzing, F. C., \& Carle, R. (2007). Effects of processing and storage on juice colour and betacyanin stability of purple pitaya (Hylocereus polyrhizus) juice. European Food Research and Technology 224(5), 649-658.

Jackman, R. I., \& Smith, J. L. (1996). Anthocyanin and Betalain. In: Henry, C. F. \& Houghton J. D. (Eds.) Natural food colorants (244-309). London, UK: Blackie Academic and Professional.

Kapur, A., Hasković, A., Čopra-Janićijević, A., Klepo, L., Topčagić, A., Tahirović, I., \& Sofić, E. (2012). Spectrophotometric analysis of total ascorbic acid content in various fruits and vegetables. Bulletin of the Chemists and Technologists of Bosnia and Herzegovina 38(4), 39-42.

Nur'Aliaa, A. R., Siti Mazlina, M. K., Taip, F. S., \& Liew Abdullah, A. G. (2010). Response surface optimization for clarification of white pitaya juice using a commercial enzyme. Journal of Food Process Engineering 33(2), 333-347.

Rebecca, O. P. S., Boyce, A. N., \& Chandran, S. (2010). Pigment identification and antioxidant properties of red dragon fruit (Hylocereus polyrhizus). African Journal of Biotechnology 9(10), 1450-1454.

Reshmi, S. K., Aravindhan, K. M., \& Suganyadavi, P. (2012). The effect of light, temperature, pH on stability of betacyanin pigments in basella alba fruit. Asian Journal of Pharmaceutical and Clinical Research 5(4), 107-110.

Reynoso, R., Garcia, F. A., Morales, D., \& Gonzalez de Mejia, E. (1997). Stability of betalain pigments from a cactacea fruit. Journal of Agricultural and Food Chemistry 45(8), 2884-2889.

Tang, C. S., \& Norziah, M. H. (2010). Stability of betacyanin pigments from red purple pitaya fruit (Hylocereus polyrhizus): influence of $\mathrm{pH}$, temperature, metal ions and ascorbic acid. Indonesian Journal of Chemistry 7(3), 327-331.

Tran, T. T. H., \& Nguyen, N. P. (2017). Economic efficiency of VIETGAP dragon fruit production in Ham Thuan district, Binh Thuan province - Current status and solutions. Journal of Forestry Science and Technology 4, 152-161.

Wong, Y. M., \& Siow, L. F. (2015). Effects of heat, pH, antioxidant, agitation and light on betacyanin stability using red-fleshed dragon fruit (Hylocereus polyrhizus) juice and concentrate as models. Journal of Food Science and Technology 52(5), 3086-3092.

Woo, K. K., Ngou, F. H., Ngo, L. S., Soong, W. K., \& Tang, P. Y. (2011). Stability of betalain pigment from red dragon fruit (Hylocereus polyrhizus). American Journal of Food Technology 6(2), 140-148. 